\title{
ANÁLISE MORFOMÉTRICA E CARACTERIZAÇÃO GEOMORFOLÓGICA DA BACIA HIDROGRÁFICA DO RIO JABOATÃO (BHRJ) - PERNAMBUCO
}

Resumo: O delineamento e caracterização morfométrica de uma bacia hidrográfica são elementos fundamentais da dinâmica deste ambiente, possibilitando contribuições no planejamento e gerenciamento dos recursos hídricos. A bacia hidrográfica do rio Jaboatão localiza-se na Mata Sul do estado de Pernambuco, incluída no grupo de pequenas bacias litorâneas. Para sua caracterização morfométrica utilizou-se os preceitos teóricos de Tonello (2005) e os procedimentos metodológicos de Christofoletti, (1980), enquanto para o mapeamento geomorfológico aplicou-se a proposta de Demek (1972). Os produtos alcançados na análise morfométrica foram segmentados em três critérios: geométrico, relevo e rede de drenagem, alguns resultados principais foram: área, perímetro, coeficiente de compacidade, declividade, hierarquia fluvial, densidade de drenagem e comprimento dos canais. $\mathrm{Na}$ caracterização geomorfológica foi mapeado três unidades morfoestruturais e seis unidades geomorfológicas para a área de estudo. Os resultados obtidos a partir dos índices morfométricos e do mapeamento geomorfológico, possibilitaram uma análise integrada da paisagem geomorfológica da bacia do rio Jaboatão.

Palavras-chave: Índices Morfométricos. Mapeamento Geomorfológico. Bacia Hidrográfica. Geomorfologia Fluvial. Rio Jaboatão.

\section{MORPHOMETRIC \\ ANALYSIS \\ AND \\ GEOMORPHOLOGICAL CHARACTERIZATION OF THE JABOATÃO RIVER BASIN \\ (BHRJ) - PERNAMBUCO}

\begin{abstract}
The design and morphometric characterization of a hydrographic basin are fundamental elements of the dynamics of this environment, enabling contributions in the planning and management of water resources. The hydrographic basin of the Jaboatão River is located in the South Forest of the state of Pernambuco, included in the group of small coastal basins. For its morphometric characterization the theoretical precepts of Tonello (2005) and the methodological procedures of Christofoletti (1980) were used, while for the geomorphological mapping the proposal of Demek (1972) was applied. The products achieved in the morphometric analysis were segmented in three criteria: geometric, relief and drainage network, some main results were: area, perimeter, coefficient of compactness, slope, river hierarchy, drainage density and channel length. In the geomorphological characterization, three morphostructural units and six geomorphological units were mapped for the study area. The results obtained from the morphometric indices and the geomorphological mapping, enabled an integrated analysis of the geomorphological landscape of the Jaboatão river basin.
\end{abstract}

Keywords: Morphometric Índices. Geomorphological Mapping. Hydrographic Basin. Fluvial Geomorphology. Jaboatão River.

\footnotetext{
${ }^{1}$ Universidade Federal de Pernambuco, Departamento de Ciências Geográficas, Recife, Brasil, csuelania.geografia@gmail.com, https://orcid.org/0000-0002-5920-867X

${ }^{2}$ Universidade Federal de Pernambuco, Departamento de Ciências Geográficas, Recife, Brasil, 


\section{ANÁLISIS MORFOMÉTRICA Y CARACTERIZACIÓN GEOMORFOLÓGICA DE LA BACIA HIDROGRÁFICA DEL RIO JABOATÓN (BHRJ) - PERNAMBUCO}

Resumen: El diseño y la caracterización morfométrica de una cuenca hidrográfica son elementos fundamentales de la dinámica de este entorno, permitiendo contribuciones en la planificación y gestión de los recursos hídricos. La cuenca hidrográfica del río Jaboatão está ubicada en el Bosque Sur del estado de Pernambuco, incluida en el grupo de pequeñas cuencas costeras. Para su caracterización morfométrica se utilizaron los preceptos teóricos de Tonello (2005) y los procedimientos metodológicos de Christofoletti (1980), mientras que para el mapeo geomorfológico se aplicó la propuesta de Demek (1972). Los productos logrados en el análisis morfométrico se segmentaron en tres criterios: geométrico, red de alivio y drenaje, algunos resultados principales fueron: área, perímetro, coeficiente de compacidad, pendiente, jerarquía fluvial, densidad de drenaje y longitud del canal. En la caracterización geomorfológica, se mapearon tres unidades morfoestructurales y seis unidades geomorfológicas para el área de estudio. Los resultados obtenidos de los índices morfométricos y el mapeo geomorfológico, permitieron un análisis integrado del paisaje geomorfológico de la cuenca del río Jaboatão.

Palabras clave: Índices morfométricos. Mapeo Geomorfológico. Cuenca Hidrográfica. Geomorfología Fluvial. Río Jaboatão.

\section{Introdução}

Os estudos sobre bacia hidrográfica estão relacionados à gestão da paisagem e ao planejamento territorial e ambiental. Para os estudos hidrológicos a bacia hidrográfica é uma área de captação de água e sedimentos, que apresenta um curso d'água principal e seus afluentes, que pós-junções, convergem para um único ponto, seu exultório (PIRES et al., 2002; TUCCI, 2009).

Foi em 1945 que o estudo e análise das bacias hidrográficas apresentou um caráter mais objetivo, principalmente após os trabalhos do engenheiro hidráulico Robert E. Horton. Suas ideias trouxeram contribuições metodológicas por propor critérios iniciais para ordenação dos cursos de d'água, incluindo a questão de hierarquia fluvial, caracterizado como um parâmetro relevante para uma análise física de uma bacia hidrográfica (HORTON, 1945; CHRISTOFOLETTI, 1980;).

No Brasil, Christofoletti (1980) propôs metodologias para análise de bacias hidrográficas, dividindo os parâmetros físicos a partir dos seguintes itens de investigação: hierarquia fluvial, análise areal, linear e hipsométrica, permitindo um entendimento abrangente e aprofundado dos ambientes hidrográficos, com ênfase para os domínios interfluviais e fluviais.

Em relação à análise morfométrica de uma bacia hidrográfica, Tonello (2005) considera os fatores geométricos, do relevo e a rede de drenagem como importantes para uma análise hidrogemorfológica. Para Teodoro et al. (2007) o estudo desses 
parâmetros físicos apresenta como objetivo esclarecer a dinâmica ambiental local e regional dentro do perímetro de uma bacia hidrográfica.

O comportamento hidrológico de uma bacia hidrográfica é determinado por meio de suas características morfológicas como: área, forma, topografia, solo, clima, geologia e cobertura vegetal. A relação destes processos no ambiente são fatores determinantes para a formação do perfil de uma bacia hidrográfica, que influenciam no processo de entrada (precipitação) e saída (escoamento) do volume hidrológico no decorrer do tempo, caracterizando as bacias de drenagem, a partir de um padrão de escoamento global (CUNHA, 2012).

Partindo dessa discussão, a pesquisa apresenta como objetivo analisar as características morfométricas e geomorfológicas da bacia hidrográfica do rio Jaboatão. O principal intuito é utilizar o conhecimento geomorfológico como instrumento de planejamento e gestão para um melhor uso e ocupação da terra, além de contribuir na propagação de maiores discussões em âmbito acadêmico a respeito dos ambientes fluviais.

\section{Área de estudo}

A Bacia Hidrográfica do Rio Jaboatão (BHRJ) está localizada na Mata Sul do estado de Pernambuco, entre as coordenadas $08^{\circ} 03^{\prime} 0^{\prime \prime}$ e $08^{\circ} 14^{\prime} 0$ " de latitudes sul e $34^{\circ} 59^{\prime} 0^{\prime \prime}$ e $35^{\circ} 15^{\prime} 30^{\prime \prime}$ de longitude oeste. A BHRJ está incluída no grupo de pequenas bacias litorâneas do estado de Pernambuco, abrangendo seis municípios: Vitória de Santo Antão, Moreno, Jaboatão dos Guararapes, São Lourenço da Mata, Cabo de Santo Agostinho e Recife (Figura 01).

Apresenta uma área territorial de cerca de $420 \mathrm{~km}^{2}$, dispondo ao rio Jaboatão uma extensão de 75 quilômetros. A nascente está localizada no município de Vitória de Santo Antão em terras a montante do Engenho Pereira, estando sua foz localizada em Barra de Jangada, bairro do município de Jaboatão dos Guararapes. Limita-se ao leste com o oceano atlântico, ao sul com a bacia do rio Pirapama, ao norte com a bacia do rio Tejipió e a oeste com a bacia do rio Capibaribe. 
Figura 01 - localização da bacia hidrográfica do rio Jaboatão

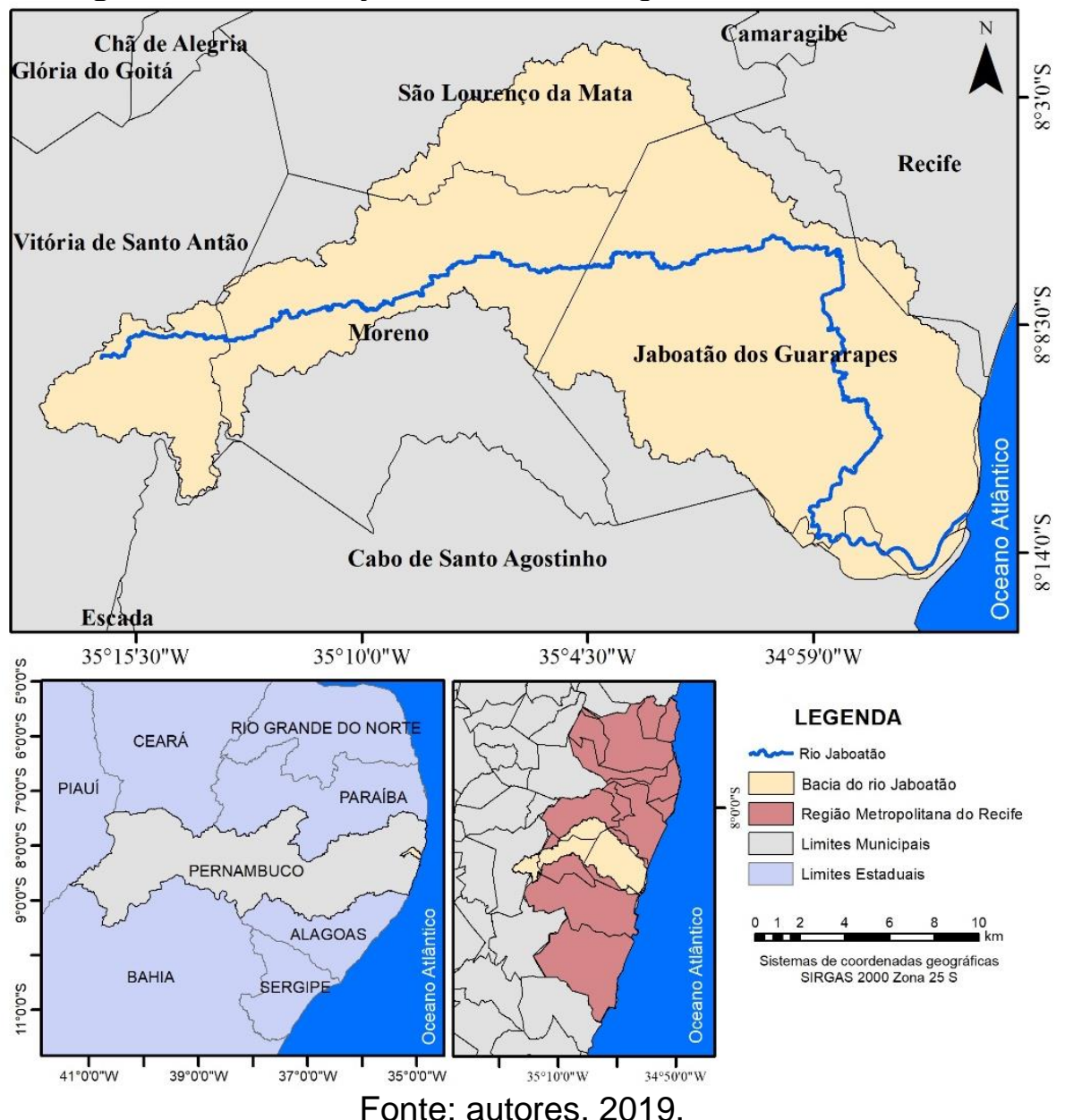

A bacia está sobre influência da massa Tropical Atlântica (mTA), que caracteriza-se por ser uma massa quente e úmida de maior influência praticamente todo ano sobre esta porção do estado. Segundo Girão, et al. (2006) a mTA sofre perturbações relacionadas aos deslocamentos da Zona de Convergência Intertropical (ZCIT) para o sul, ocorrência de Vórtices Ciclones de Altos Níveis (VCAN) e chegada de fluxos da Frente Polar Atlântica, como também os Distúrbios Ondulatórios de Leste (DOL), caracterizados como sistemas de forte influência para a geração de chuvas na bacia.

A dinâmica de precipitação demonstra que o período de maior pluviosidade concentra-se entre os meses de abril a julho, atentando-se especificamente aos meses de junho e julho, quando a média mensal pode chega a aproximadamente $400 \mathrm{~mm}$. O início desse inverno austral é caracterizado como crítico para a população que reside em áreas de riscos, deixando-as sempre em alerta; já o período seco, caracterizado por baixas pluviosidades, ocorre nos meses de setembro a novembro, quando também decorre um aumento relativo da temperatura. 
A bacia hidrográfica do rio Jaboatão se distribui por oito unidades geológicas, sendo "cortada", ao norte, pela Zona de Cisalhamento Pernambuco, e composta pelo Complexo Belém de São Francisco, Complexo Salgadinho, Granitoides Indiscriminados, Depósitos Aluvionares, Depósitos Flúvio-marinhos, Depósitos Colúvio-aluviais, Plúton sem denominação e a Formação Barreiras.

$\mathrm{Na}$ área de estudo são identificadas sete classes pedológicas. Os Argissolos Vermelho-amarelo, Latossolos Amarelos e Argissolos Amarelos compreendem maior parte da bacia e estão localizados na unidade geomorfologia das colinas. Os Gleissolos Háplicos estão presentes nos canais fluviais, enquanto os Neossolos Lítolicos, Neossolos Quartzarenicos e os solos de mangue estão presentes nas planícies do baixo curso da bacia.

Os principais usos da terra nessa bacia são: agropecuária, localizada nos domínios das colinas, no alto e médio curso, com presença principalmente do cultivo da cana-de-açúcar e pastagem. Nas áreas de baixo curso o uso é majoritariamente urbano, com alguns centros comerciais, industriais e residenciais. Exceção a esse uso majoritário são algumas áreas marginais ao rio Jaboatão onde se verifica vegetação do tipo arbórea e manguezais.

\section{Material e métodos}

O estudo dos índices morfométricos é relevante no sentido de contribuir como mais uma ferramenta para o conhecimento da dinâmica fluvial e avaliação das condições destes ambientes. Diante disto, o presente trabalho baseou-se na organização dos índices propostos por Tonello (2005), que divide a morfometria da bacia hidrográfica em três grupos de análise: características geométricas, do relevo e da rede de drenagem.

\section{Características geométricas}

Para uma análise geométrica da bacia são incorporados alguns índices como: área, perímetro, padrão de drenagem e coeficiente de compacidade. Área da bacia é o total que compreende toda área que compõe o sistema de drenagem de uma bacia hidrográfica, projetada em um plano horizontal (CHRISTOFOLETTI, 1980). O perímetro da bacia constitui na maior distância em linha reta da foz a um determinado ponto do perímetro, e também o comprimento da linha imaginária ao longo do divisor de água (TONELLO, 2005). 
Segundo Christofoletti (1980) o padrão de drenagem é a organização espacial dos cursos fluviais. Um padrão pode ser formado por uma ou mais bacias de drenagem, sendo este padrão determinado a partir do critério geométrico, um importante elemento para classificação de bacias hidrográficas. O coeficiente de compacidade é um índice relacionado ao fator de forma, expresso pela relação entre o perímetro da bacia e o perímetro de um círculo de que apresente a mesma área.

\section{Características do relevo}

Os elementos relacionados ao relevo são: hipsometria e declividade, utilizando como base o modelo digital de elevação SRTM. A declividade é expressa pela inclinação da superfície do terreno em comparação a horizontal, expõe a relação da diferença de altitude entre dois pontos e a distância horizontal desses mesmos pontos (IBGE, 2009). A confecção da declividade é realizada a partir do MDE, imagem SRTM, utilizando a ferramenta Slope, presente no Arctoolbox, do software ArcGis 10.3 .

\section{Características da rede de drenagem}

A drenagem foi extraída a partir do modelo digital do terreno (MDT), utilizando as ferramentas do ArcHydro. Após a extração da drenagem da bacia foi possível delimitar o comprimento de todos os canais. Em seguida foi realizada a hierarquia fluvial, que se baseia na classificação de um curso d'água, determinando a ordem e grau dos canais fluviais que estão presentes em uma bacia hidrográfica.

Strahler (1952) propôs classificação cujos canais de primeira ordem são os menores e não recebem tributários. Canais de segunda ordem ocorrem da junção de dois canais de primeira ordem e assim sucessivamente, podendo eles receberem afluentes de menor ordem (CHRISTOFOLETTI, 1980). No caso do método de Strahler, este pode ser obtido através da ferramenta Stream Order, disponível no software Arcgis 10.3.

A densidade de drenagem é um parâmetro importante na análise das condições de drenagem de uma bacia, ou seja, avalia-se o quanto essa drenagem é eficiente em relação a capacidade de escoamento. É obtida por meio da relação entre o comprimento total dos canais e a área total da bacia. Para estabelecer a densidade de drenagem é utilizada a fórmula, proposta por Horton (1945): $\mathrm{Dd}=\frac{L t}{A}$ 
Dd: densidade da drenagem, Lt: comprimento total dos canais e A: área da bacia. (CHISTOFOLETTI, 1980: STEVAUX, 2017).

Segundo Chistofoletti (1980) o índice de sinuosidade do canal é expresso pela relação entre o comprimento do canal e a distância do eixo do vale. Expressa pela formula: Is $=\frac{L}{D v}$ Is: índice de sinuosidade, L: é o comprimento do canal principal, Dv: distância vetorial entre os pontos extremos do canal principal (comprimento em linha reta) (Schumm, 1977). Para a classificação considera-se que valores acima de 1,5 os canais são sinuosos (meândricos) e abaixo desse valor eles tendem a serem mais retilíneos.

\section{Mapeamento morfoestrutural e geomorfológico}

A definição das morfoestruturas e das unidades geomorfológicas tem como objetivo a representação do relevo em diferentes escalas e a compreensão da dinâmica da paisagem. Este estudo busca o conhecimento dos processos e das formas geradas, como também da sua dinâmica evolutiva (SILVA, 2016).

Segundo Saadi (1991) os domínios morfoestruturais caracterizados como compartimentos geomorfológicos recebem influência direta da litologia e da estrutura geológica. Para definição das morfoestruturas utilizou-se como embasamento metodológico o trabalho de Fonsêca et al., (2016), que realizou análise morfoestrutural da Região Metropolitana do Recife-PE.

Para o mapeamento geomorfológico foram utilizados os trabalhos de Fonsêca (2012) e Silva (2016). Isto por que as pesquisas realizadas por esses autores são localizadas em áreas próximas a bacia do rio Jaboatão, com características geomorfológicas semelhantes, sendo possível associar esses estudos na definição das nomenclaturas das unidades de relevo.

Os mapeamentos foram realizados com base no Modelo Digital do Terreno (MDT), a partir de uma análise conjunta com outros mapeamentos-bases como: declividade, curvas de nível e geologia. Os mapeamentos foram realizados no software ArcGis 10.3. A metodologia utilizada para o mapeamento geomorfológico foi a proposta da União Geográfica Internacional (UGI), descrita por Demek (1972), na escala de 1:100.000. 


\section{Resultados e discussões}

\section{Análise morfométrica}

A bacia hidrográfica do rio Jaboatão possui uma área de drenagem de 420 $\mathrm{km}^{2}$ e um perímetro de $190,34 \mathrm{~km}$. Esses dados de área representam todo o desenvolvimento do sistema fluvial do rio Jaboatão, sendo também um importante elemento para o entendimento da densidade de drenagem e do coeficiente de compacidade da bacia (Tabela 01).

Tabela 01: Morfometria da BHRJ.

\begin{tabular}{ccc}
\hline CARACTERÍSTICAS & ÍNDICES MORFOMÉTRICOS & RESULTADOS \\
\hline \multirow{2}{*}{ Geométricas } & Área da Bacia & $420 \mathrm{~km}^{2}$ \\
& Perímetro da Bacia & $190,34 \mathrm{~km}$ \\
& Escoamento fluvial & Exorréico \\
& Padrão de drenagem & Dendrítico \\
& Coeficiente de compacidade & 2.6 \\
Relevo & Declividade mínima & $0 \%$ \\
& Declividade máxima & $97,28 \%$ \\
& Altitude mínima & $0 \mathrm{~m}$ \\
& Altitude máxima & $445 \mathrm{~m}$ \\
Rede de drenagem & Ordem dos Canais & $5^{\circ}$ ordem \\
& Densidade de drenagem & $1,62 \mathrm{Km} / \mathrm{km}^{2}$ \\
& Índice de sinuosidade do canal principal & $1,99(\mathrm{Canal}$ \\
& Comprimento do canal principal & sinuoso $)$ \\
& Comprimento de todos os canais & $75 \mathrm{~km}$ \\
\hline
\end{tabular}

Fonte: Autores, 2019.

O escoamento fluvial da bacia hidrográfica é do tipo exorréico, estando sua foz no oceano Atlântico Sul. Apresenta padrão de drenagem dendrítico em que o canal principal representa o "tronco" e os afluentes aos "ramos de uma árvore", reflexo de um controle estrutural. É possível identificar na bacia hidrográfica em questão algumas anomalias nas confluências dos canais por apresentarem ângulos retos.

O coeficiente de compacidade da BHRJ é de 2,6, expressando que a bacia não está sujeita a amplas inundações. Esse índice está diretamente ligado a forma do perímetro da bacia hidrográfica que, nesse caso, apresenta uma configuração alongada e, portanto, de baixa susceptibilidade a inundações. Entretanto, mesmo a BHRJ não estando sujeita a inundações, segundo o coeficiente de compacidade, existe a ocorrência de picos de enchentes e possíveis extravasamentos em algumas áreas da bacia nos períodos chuvosos. 
A ocorrência das enchentes e inundações precisam ser analisadas juntamente com outros fatores como: formas de uso e ocupação da terra; maior concentração de fluxo no baixo curso; impermeabilização do solo e ocupação de áreas marginais; trecho retificado devido a presença de lineamentos, contribuindo para o aumento da velocidade de escoamento; índices acentuados de precipitação durante o período de outono-inverno austral (março-setembro).

A BHRJ apresenta altitudes entre 0 a 445 metros (Figura 02). Os diferentes valores altimétricos expressam as formas de relevo presentes no domínio fluvial e interfluvial. Para a bacia hidrográfica em questão essas cotas altimétricas mostram relevo de baixa altitude, caracterizando-se, em sua maioria de planícies e colinas.

Figura 02 - Hipsometria da BHRJ.

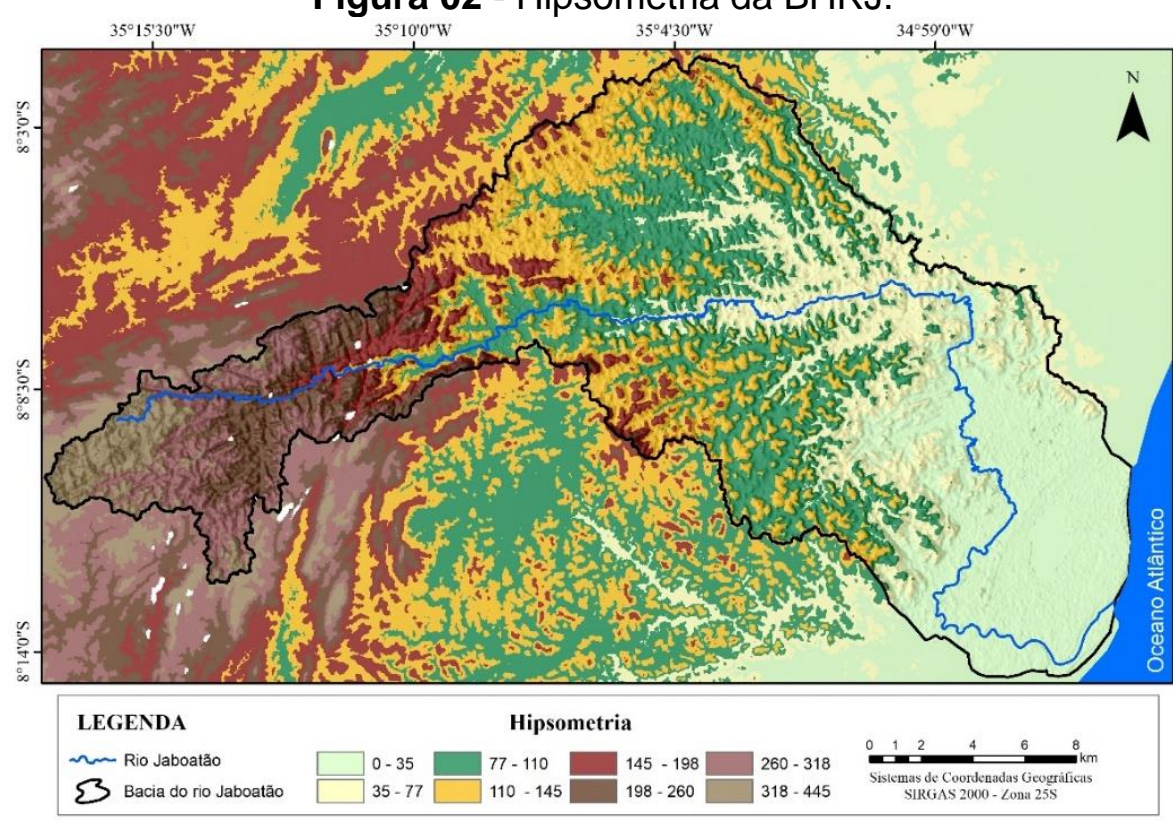

Fonte: Autores, 2019.

A declividade apresenta-se acentuada nas áreas de alto e médio curso, com valores entre 20 a 75\%, sendo reduzida nas áreas de baixo curso com característica de relevo de planície, entre 0 a $8 \%$ (Figura 03). Os valores percentuais dos desníveis expressos no terreno permitem classificar o relevo dessa bacia hidrográfica, em sua maioria, de ondulado a forte ondulado (EMBRAPA, 2006). 


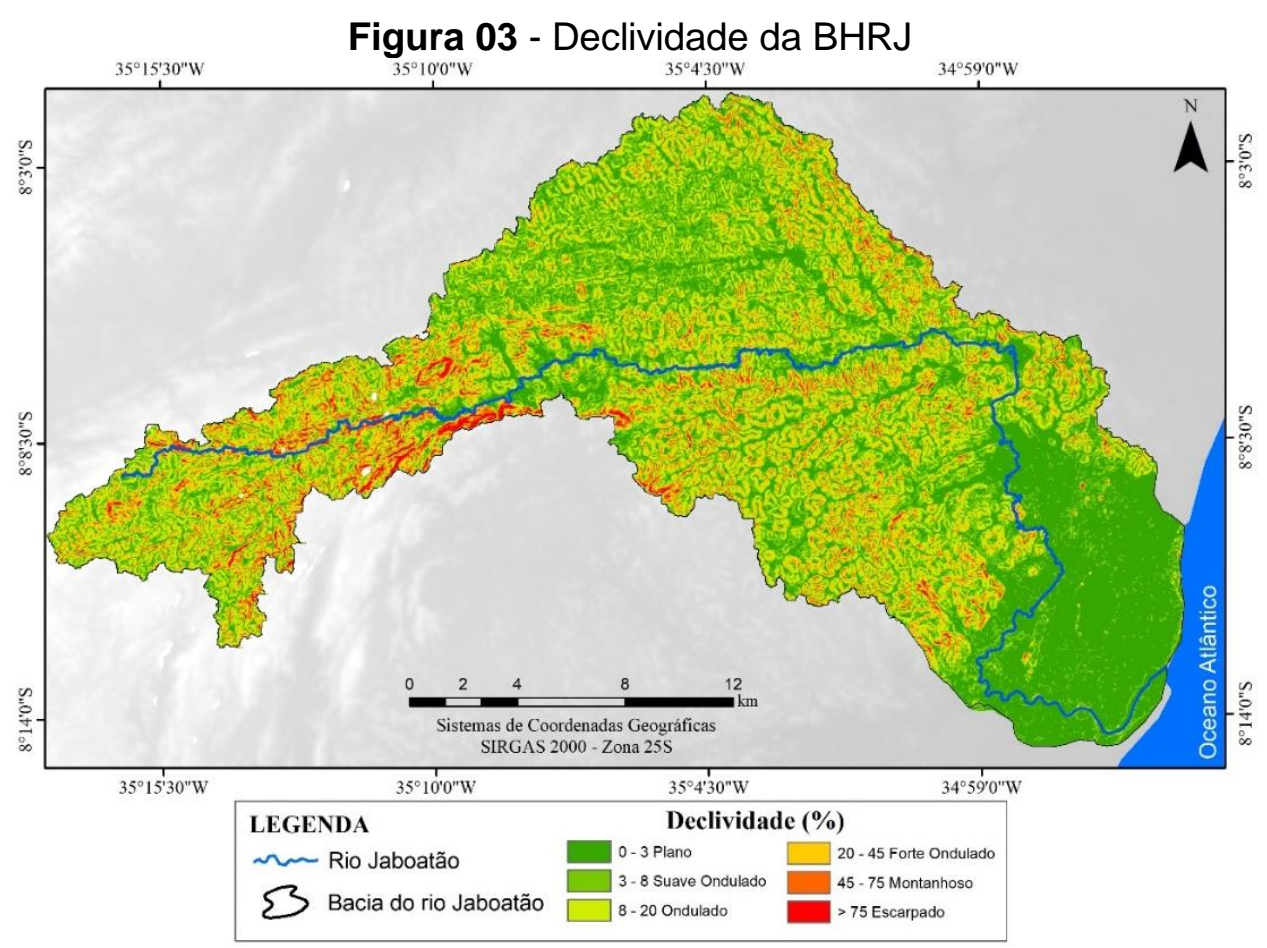

Fonte: Autores, 2019.

A declividade é um importante fator para a velocidade do escoamento superficial em domínio interfluvial, assim como sobre o tempo em que a água e os sedimentos escoados chegam ao canal fluvial. Nesses compartimentos o escoamento superficial é rápido, e em detrimento da infiltração, ocasionando a incidência de processos erosivos e movimentos de massa com maior ênfase se comparado as ocorrências nos interflúvios do baixo curso.

Além da relevância a nível areolar, a declividade é um importante fator na análise das encostas como lócus ocupacionais. Isto porque exerce influência tanto na ativação de processos erosivos e movimentos de massa quanto nas formas de uso e ocupação da terra.

No alto e médio curso da BHRJ áreas de maior declividade apresentam-se com plantio de cana-de-açúcar, pastagem e também com áreas urbanas, principalmente destinadas a moradias. Quanto aos ambientes plantados, nos períodos de corte da cana-de-açúcar (setembro a março), que coincide com o período chuvoso do litoral oriental nordestino, o solo, principalmente os Argissolos, fica desprotegido de vegetação. Isso facilita a ocorrência de processos erosivos lineares na ocorrência de eventos chuvosos.

Nas áreas destinadas a moradia, os elementos do relevo (altitude e declividade) além de fatores climáticos, com ênfase para as precipitações, contribuem para a susceptibilidade e intensificação de eventos relacionados à dinâmica superficial de encostas. Esses também caracterizam em áreas de risco, 
que anualmente, nos meses de maio a julho, é verificada a gênese de feições erosivas e ocorrências de movimentos de massa, sobretudo do tipo escorregamento.

A BHRJ é constituída do canal principal, o rio Jaboatão com $75 \mathrm{~km}$ de extensão e pelos seus afluentes (Figura 04). Os principais afluentes da margem esquerda são: rio Duas Unas com $29 \mathrm{~km}$, rio Mussaíba com $13,5 \mathrm{~km}$, rio Macaco com 9,2 km e o rio Pixaó com 11,6 km. Na margem direita encontram-se os rios Mangaré com 14,9 km e o riacho do Arroz com 11,5 km.

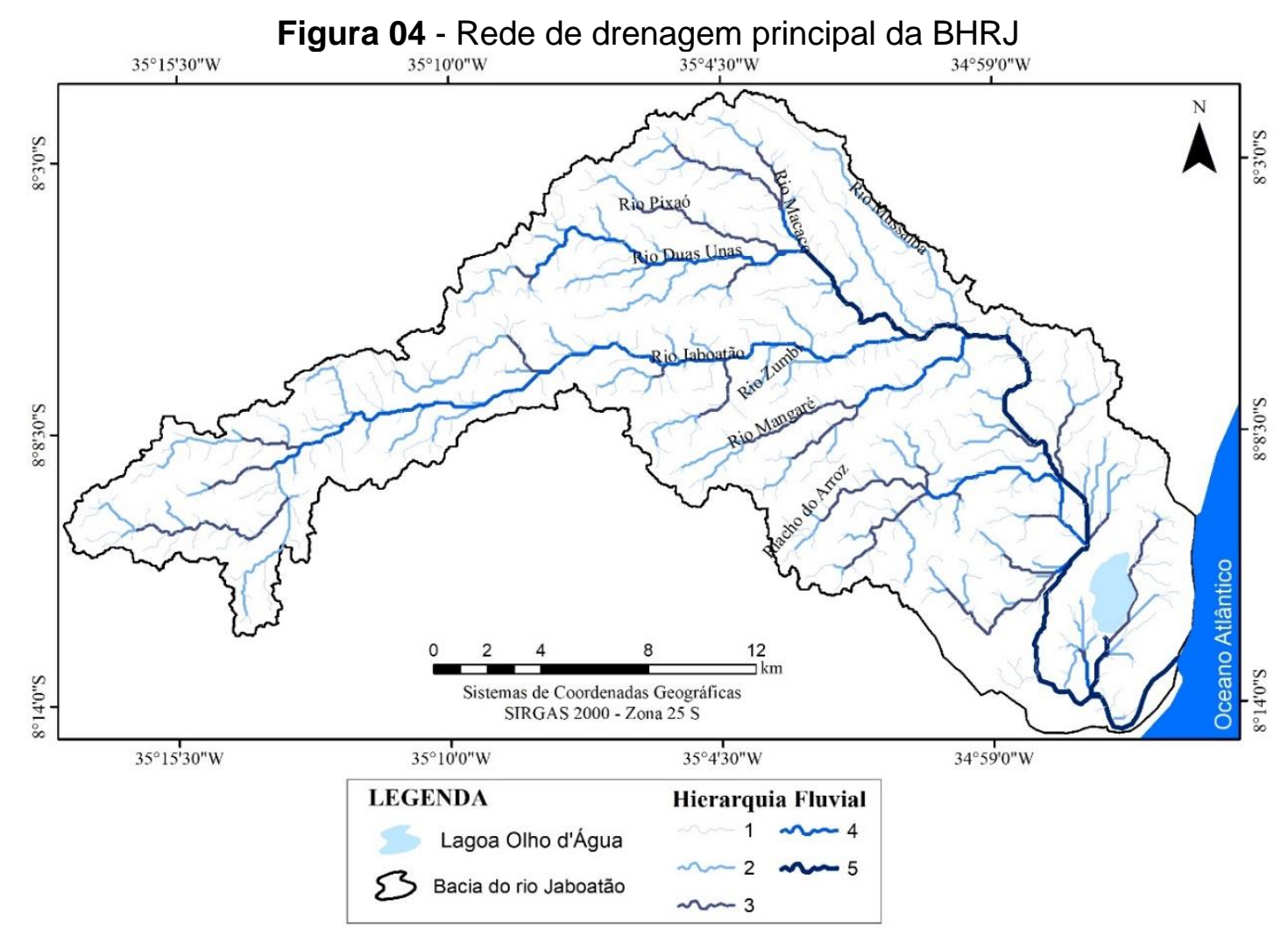

Fonte: Autores, 2019.

A bacia do rio Jaboatão possui uma área drenada pela Lagoa Olho d'Água (Figura 04), um sistema lagunar com $3,7 \mathrm{~km}^{2}$ de área, que apresenta ligação com dois canais: o canal de Setúbal ao norte e o canal Olho d'Água ao sul que é um afluente do rio Jaboatão e desagua na lagoa (CPRM, 1997). A lagoa Olho d'Água está inserida no contexto urbano da bacia do rio Jaboatão, com acentuada ocupação de baixa renda nas margens que intensificam o lançamento de resíduos sólidos e águas servidas diretamente na lagoa.

A densidade de drenagem da bacia em questão é de $1,62 \mathrm{~km} / \mathrm{km}^{2}$. Segundo Villela e Mattos (1975), os valores de densidade de drenagem indicam o grau de desenvolvimento de um sistema fluvial, devido à relação entre a extensão de todos os canais com a área total da bacia. Os valores podem variar entre $0,5 \mathrm{~km} / \mathrm{km}^{2} \mathrm{com}$ drenagem pobre, a maiores que 3,5 para áreas bem drenadas. 
Considerando o valor da densidade de drenagem para esta bacia hidrográfica a drenagem é caracterizada como mediana. Características como litologia de rochas resistentes, juntamente com os controles pedológicos e cobertura vegetal influenciam em uma boa drenagem e no padrão de escoamento da área.

A bacia do rio Jaboatão apresenta uma hierarquização de $5^{\circ}$ ordem (Figura 04), sendo 552 canais de $1^{\circ}$ ordem, 134 canais de $2^{\circ}$ ordem, 32 canais de $3^{\circ}$ ordem, 7 canais de $4^{\circ}$ ordem e 2 canais de $5^{\circ}$ ordem que são o rio Jaboatão e o rio Duas Unas. Evidencia-se um número elevado de canais de primeira ordem. Segundo Christofoletti (1980), quanto maiores os percentuais de canais de primeira ordem, maior também será a dissecação do relevo.

\section{Caracterização geomorfológica da bacia do rio Jaboatão}

A caracterização geomorfologia da bacia do rio Jaboatão permitiu uma análise dos elementos que compõem a paisagem dessa área, como a estrutura geológica e a declividade, atrelado aos fatores do clima e da rede de drenagem que contribuem como agentes superficiais da dinâmica geomorfológica. Na bacia em questão foram reconhecidos três domínios morfoestruturais e seis unidades geomorfológicas, possibilitando assim analise da paisagem sobre diferentes escalas geomorfológicas.

O termo morfoestrutura indica os compartimentos geomorfológicos que são nitidamente controlados pelo arcabouço litológico e estrutural. Constituídos por tipologias relacionadas ao relevo de forma hierárquica, estas são compostas por conjuntos regionais de primeira ordem, até os de menores grandezas. Nas morfoestruturas é importante observa-las a partir da análise regional da paisagem, relacionando as estruturas geológicas e as feições morfológicas de primeira ordem de grandeza presentes na superfície (FONSÊCA et al., 2016; SAADI, 1991).

Para a bacia hidrográfica em questão as unidades morfoestruturais (Figura 05), são: o Piemonte Cristalino da Borborema, correspondendo a uma área de $328 \mathrm{~km}^{2}$ na BHRJ, o que significa $78 \%$ da área territorial, localizado na área de cabeceira de drenagem até as partes do médio curso da bacia; o Planalto sedimentar litorâneo, que compreende uma pequena área da $B H R J$ de $7,8 \mathrm{~km}^{2}$, refletindo apenas $2 \%$ da área total, localizado a NE da BHRJ; e a Planície flúvio-marinha, compondo $19 \%$ da área, correspondente a $80 \mathrm{~km}^{2}$, localizada a SE da bacia. 
Figura 05 - Unidades morfoestruturais da BHRJ

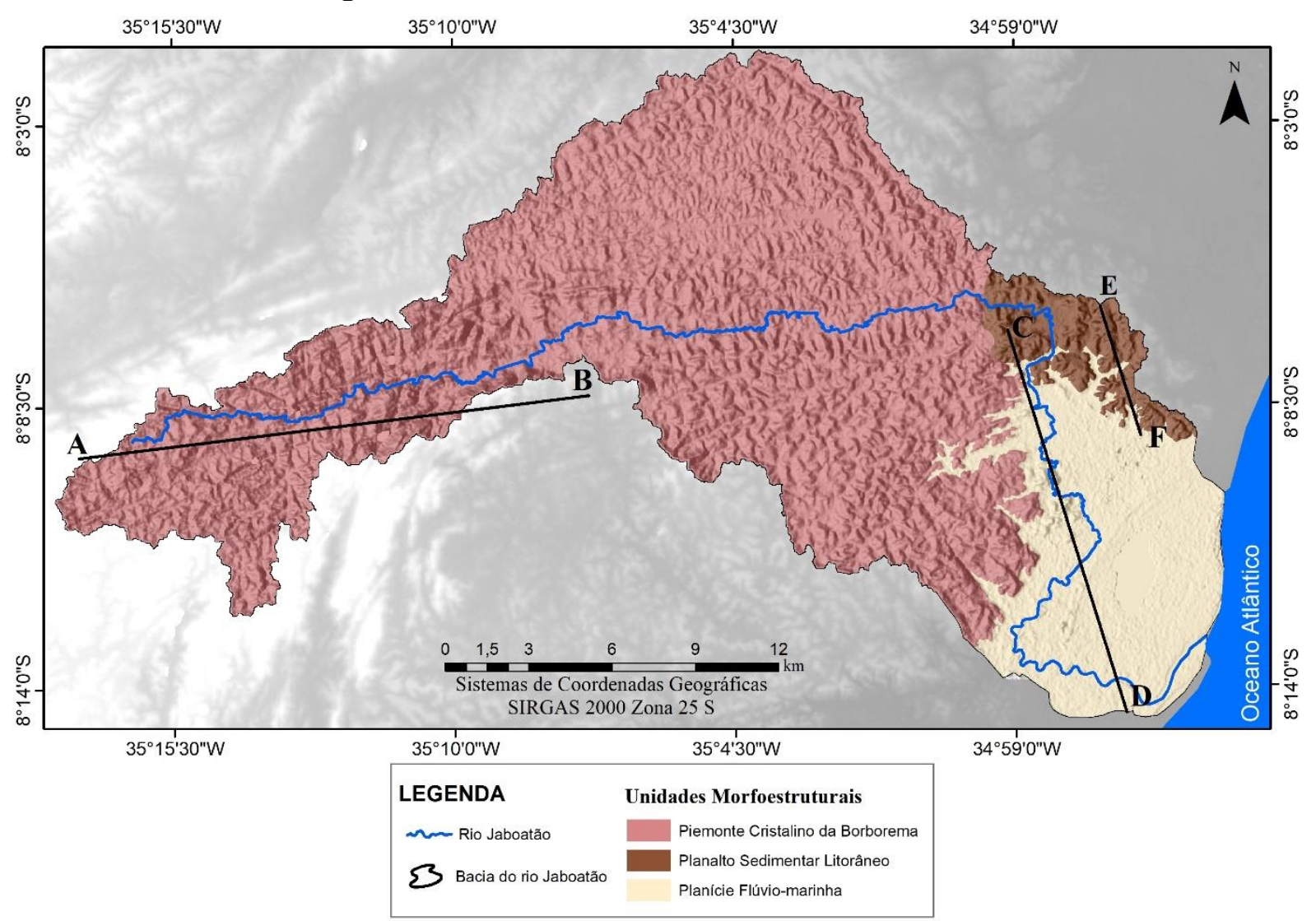

Fonte: Autores, 2019.

O Piemonte Cristalino da Borborema é caracterizado por ter sofrido processos mais intensos de denudação. Pois apresenta uma drenagem dendrítica, exibindo trechos de rios retilíneos que foram condicionados pelas estruturas lineares subjacentes. Atualmente é composto por litologia mais profunda do complexo cristalino, com um relevo rebaixado, constituído por estruturas herdadas das litologias.

O Piemonte Cristalino da Borborema (Figura 06) está entre as cotas de 100 a 450 metros, classificado como unidades pluriconvexas. Nas altitudes acima dos 300 metros, nos municípios de Vitória de Santo Antão e Moreno, as formas apresentam topos mais aguçados com vales fechados em formato "V". Nas cotas mais rebaixadas em direção ao litoral, principalmente nos municípios de São Lourenço da Mata e Jaboatão dos Guararapes, as formas são arredondadas e com vales abertos, sofrendo maior processo de dissecação. 
Figura 06 - Perfis longitudinais dos compartimentos morfoestruturais

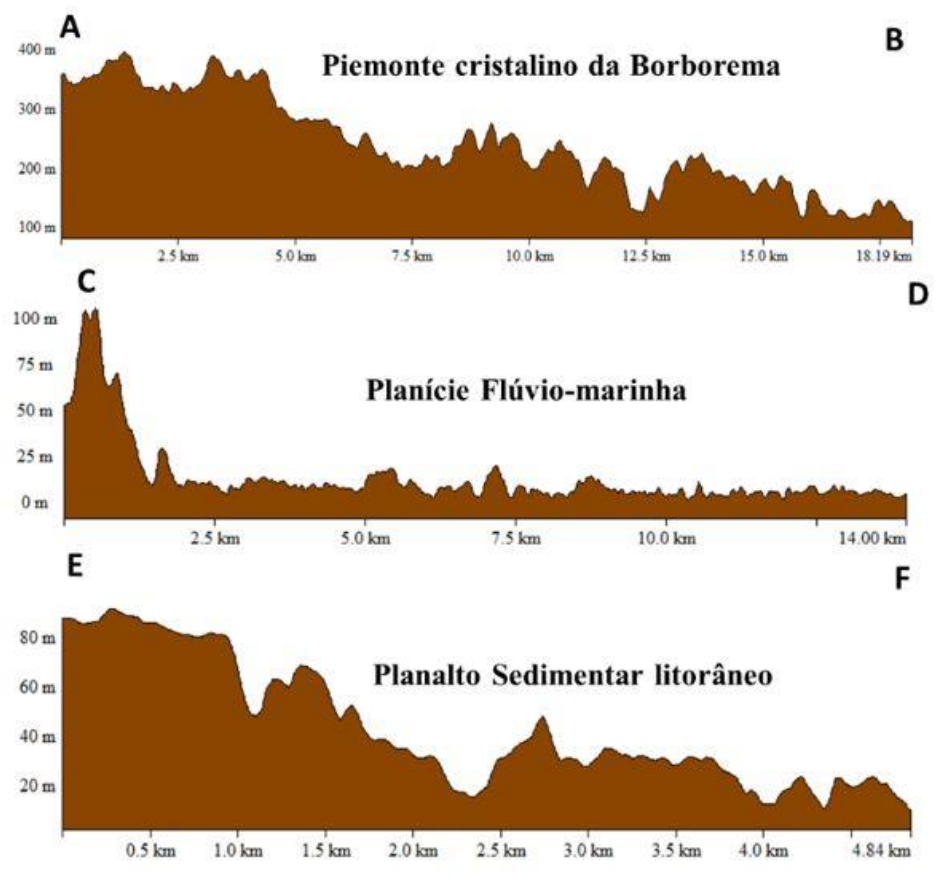

Fonte: autores, 2019.

O Planalto Sedimentar Litorâneo ocorre principalmente ao norte do Lineamento Pernambuco, porém existe alguns fragmentos ao sul deste lineamento, como acontece em uma pequena porção da BHRJ, estando estes fragmentos relacionados aos sedimentos da Formação Barreiras. Nestas unidades o grau de dissecção aumenta em direção à costa, expondo morfologia de topo amplo e tabular, com vales profundos abertos.

Analisando o transecto desta unidade na figura 06, a amplitude altimétrica está entre 20 a 100 metros, sendo esta unidade caracterizada por uma morfologia do tipo tabular. Nas altitudes ente 60 a 100 metros, apresenta-se mais conservada, enquanto nas altitudes inferiores ocorre um maior processo de dissecação. Isso é possível evidenciar também em relação aos tabuleiros localizados ao norte do lineamento, que são menos dissecados, devido ao fato que na porção ao sul do lineamento a densidade de drenagem é expressiva, se comparada a verificada ao norte do lineamento Pernambuco.

A unidade morfoestrutural da Planície Flúvio-marinha foi gerada pelo processo de deposição de sedimento fluvial do rio Jaboatão e de sedimentos do cordão litorâneo. Nesta unidade também encontram-se os sedimentos de baixios de maré e os lagunares. Esse domínio determina uma morfologia plana, em torno dos 10 metros de altitude, como ocorre no baixo curso da BHRJ, onde a amplitude altimétrica não ultrapassa os 20 metros de altitude. 
Para a bacia em questão as unidades geomorfológicas encontradas foram: colinas com $72 \%$, sendo subdividas em duas subunidades a partir das formas de dissecação atrelados a resistência do material, diferenciando-as pelo vale e altitude; a unidade das planícies, compondo $23,81 \%$ da área, subdivididas em três, sendo diferenciadas a partir do seu ambiente de deposição, e a unidade do tabuleiro sedimentar dissecado, com 4,25\% da área da BHRJ (Tabela 02).

Tabela 02 - Área territorial das unidades geomorfológicas na bacia do rio Jaboatão

\begin{tabular}{|ccc|}
\hline Unidades geomorfológicas & $\begin{array}{c}\text { Área territorial } \\
\mathbf{( k m}^{\mathbf{2}}\end{array}$ & $\begin{array}{c}\mathbf{( \% )} \text { na bacia do } \\
\text { rio Jaboatão }\end{array}$ \\
\hline Colinas de topos convexos e vales fechados & 144,36 & 34,37 \\
Colinas de topos convexos e vales abertos & 158,14 & 37,65 \\
Planície Aluvial & 45,23 & 10,76 \\
Planície Flúvio-marinha & 46,74 & 11,12 \\
Planície Costeira & 8,07 & 1,93 \\
\hline Tabuleiro sedimentar dissecado & 17,85 & 4,25 \\
\hline
\end{tabular}

Fonte: autores, 2019.

Foram traçados perfis longitudinais para cada unidade geomorfológica (Figuras 07 e 08) como forma de representação dessas unidades, contribuindo para melhor visualização destas formas na paisagem.

Figura 07 - Unidades geomorfológicas da BHRJ

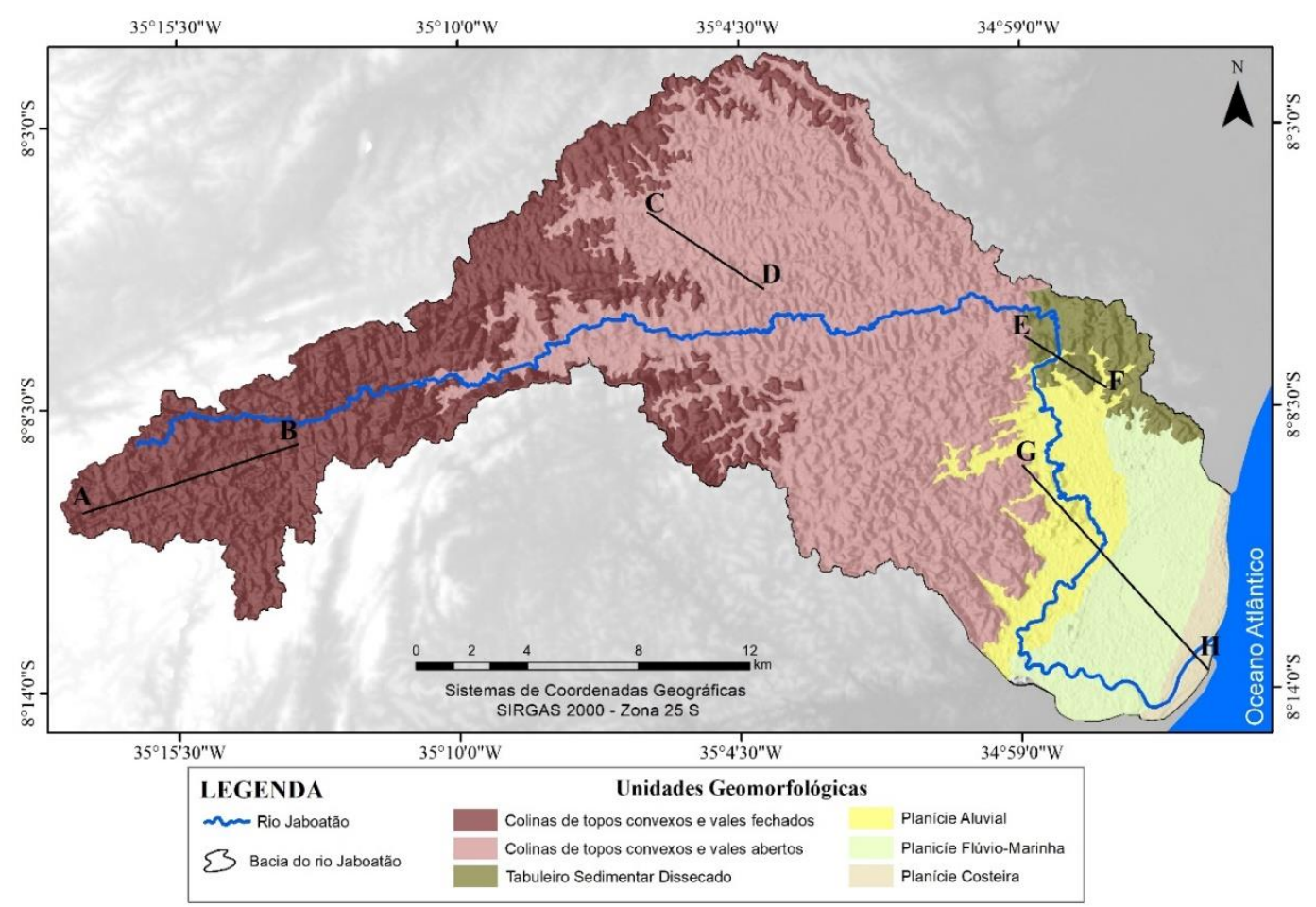

Fonte: Autores, 2019. 
Figura 08 - Perfis longitudinais das unidades geomorfológicas

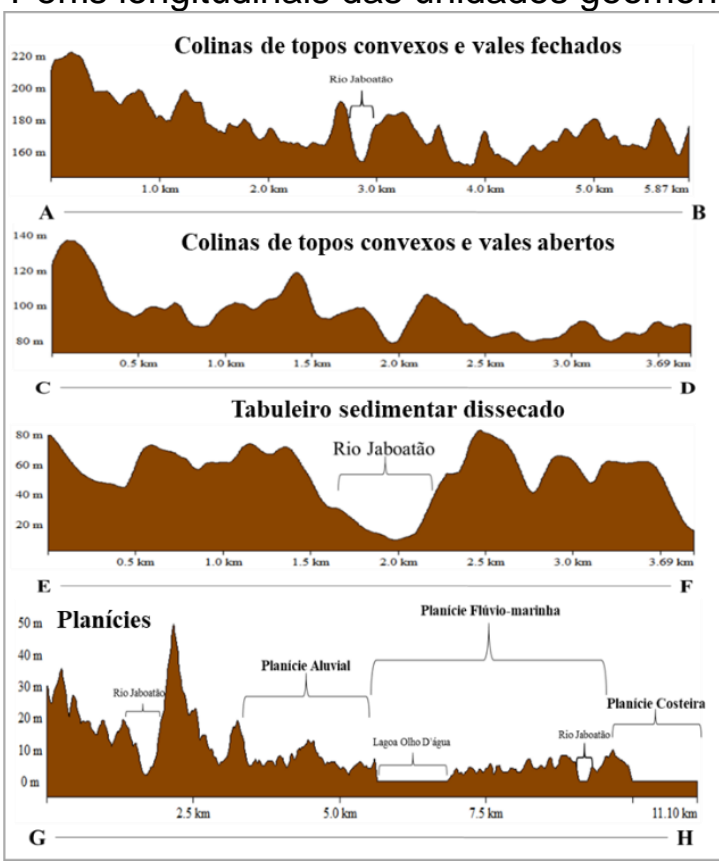

Fonte: autores, 2019.

A unidade geomorfológica das colinas compreende a maior área territorial da bacia, formada sobre uma geologia datada do Proterozóico, com rochas metamórficas e ígneas, presentes em sua maioria nos complexos Salgadinho e Belém de São Francisco. Estão localizadas principalmente na parte central da bacia, nas regiões de alto e médio curso. As colinas possuem uma morfologia pluriconvexa com altitudes de até 445 metros.

Foram subdividas em duas unidades, para melhor compreensão do processo de dissecação do relevo, relacionada tal subdivisão, principalmente, com a altitude e declividade destas feições. Importante ressaltar que o processo de denudação vai tornando-se maior nesta unidade em direção a linha de costa devido ao aumento das médias pluviais, o processo de erosão fluvial é bastante intenso.

As colinas de topos convexos e vales fechados são encontradas principalmente no município de Vitória de Santo Antão e Moreno. Possuem altitudes que variam de 145 a 445 metros, expõem uma morfologia de colinas com topos aguçados convexos e os vales são fechados e declivosos, com profundidade acentuada em áreas de cabeceiras de drenagem (Figura 09A).

As colinas de topos convexos e vales abertos inserem-se nos municípios de Moreno, Jaboatão dos Guararapes e São Lourenço da Mata. Apresentam cotas altimétricas de 80 a 145 metros, são individualizadas pela altitude, como também pelos vales que são mais abertos. Esta subunidade sofre maior processo de dissecação fluvial do que as unidades anteriores (Figura 09B). 
As planícies estão localizadas no baixo curso da bacia do rio Jaboatão (Figura 09C), caracterizadas por superfícies planas e rebaixadas, com altitudes de até 20 metros. Os depósitos possuem material superficial de sedimentos inconsolidados. Foi subdividida em três unidades de planícies (Figura 08), a saber: a planície aluvial, composta por depósitos aluvionares referentes ao rio Jaboatão; a planície flúviomarinha, constituída por deposito colúvio-eluvionares e depósitos flúvio-marinho, e a planície costeira, formada por depósitos de sedimentos marinho.

As áreas de tabuleiro sedimentar dissecado estão localizadas entre Recife e Jaboatão dos Guararapes, sendo feições constituídas de material inconsolidado da Formação Barreiras, apresentando dissecação fluvial e altitudes médias entre 60 a 80 metros, estando presente em áreas próximas ao litoral. A morfologia destas feições é de topos planos em formato tabular, caracterizando-se por apresentarem um modelado tabular dissecado (Figura 09D).

Figura 09: Unidades geomorfológicas. A: Colinas de topos convexos e vales fechados; B Colinas de topos convexos e vales abertos; C Planícies; D Tabuleiro sedimentar dissecado.

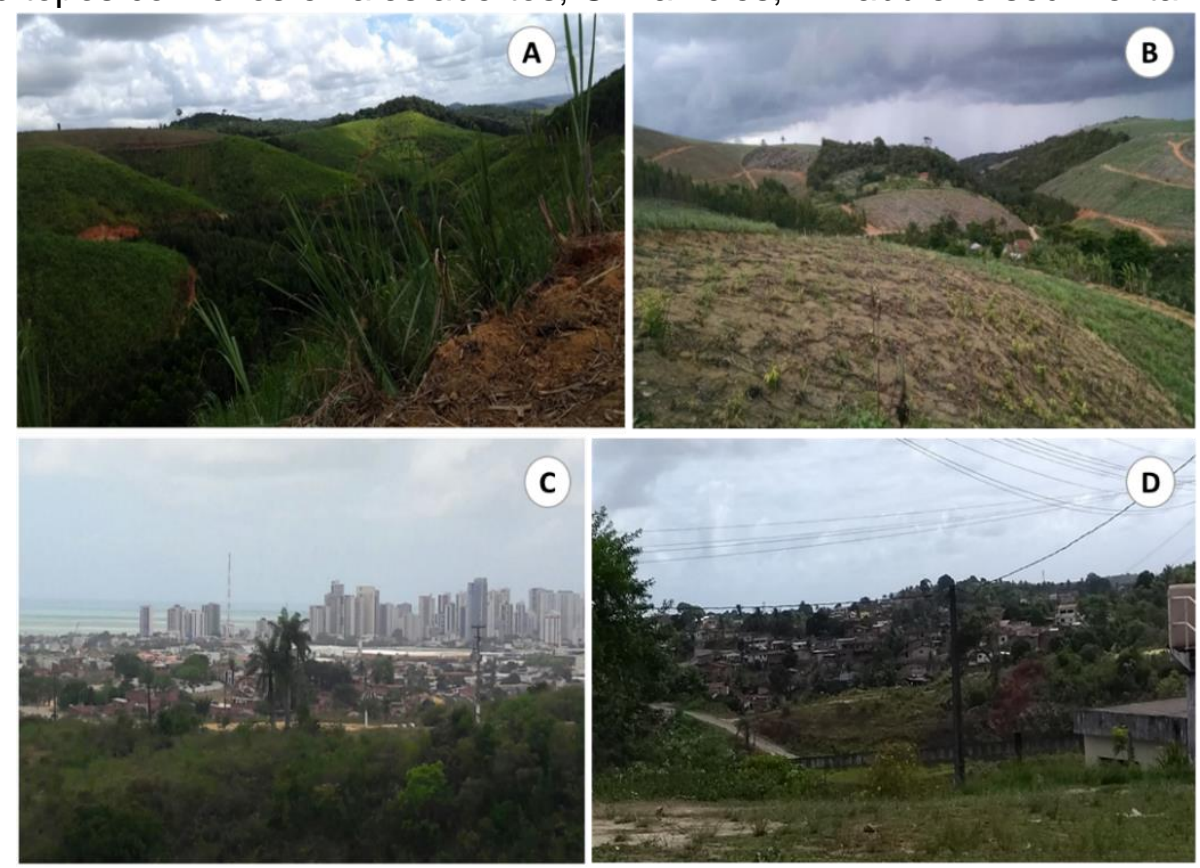

Fonte: autores, 2019.

\section{Considerações Finais}

A bacia hidrográfica do rio Jaboatão exibe uma forma estreita na sua parte inicial, sendo alargada à medida que se direciona para sua foz. Apresenta uma diversidade de características seja na sua morfometria e na geomorfologia, atribuindo aspectos diferenciados a sua paisagem.

O sistema hidrológico da bacia é mediano, sendo bem distribuído na sua área territorial, com um predomínio de canais de primeira ordem, atrelado a contribuição 
dos fatores climáticos e declividade que levam as áreas interfluviais a promoveram uma maior produção de sedimentos. As áreas de maior concentração de fluxo na bacia são os ambientes rebaixados e próximos ao canal principal ou próximas das confluências com outros canais, contribuindo na ocorrência de extravasamento do fluxo presente no leito durante eventos intensos de precipitação.

A área de estudo apresenta uma dinâmica geomorfológica de intensos processos de denudação atuais e pretéritos, sobretudo relacionados com as características climáticas e com a erosão fluvial. Em sua maioria composta por um relevo com superfícies colinosas de altitudes médias, de topos convexos e vale ora fechados e ora abertos, localizadas principalmente no alto e médio curso.

Nas áreas de baixo curso da bacia do rio Jaboatão, próximas ao oceano Atlântico, a geomorfologia é predominante de planície, com relevo rebaixado e formada principalmente de material inconsolado. $O$ intenso processo de ocupação nas planícies transforma o modelado como também os canais fluviais nessas áreas causando, por vezes, canalização, retificação e colmatação de sedimentos.

O mapeamento geomorfológico é um importante instrumento na representação das formas da superfície terrestre. Mapear e compreender as unidades geomorfológicas presentes na bacia hidrográfica em foco trouxeram contribuições para uma avaliação e análise eficiente das condições geomorfológicas relacionandose, para tanto, com os aspectos geológicos, hipsométricos, climáticos e de declividade.

\section{REFERÊNCIAS}

CHRISTOFOLETTI, A. Geomorfologia. São Paulo: Edgard Blucher, 1980, 189p.

CHISTOFOLETTI, Antônio. Geomorfologia Fluvial, Ed. Edgard Blücher, São Paulo, 1981, $297 p$.

CUNHA, Sandra Baptista da. Geomorfologia Fluvial. In: Geomorfologia: Uma Atualização de Bases de Conceitos. S. B. CUNHA; A. J. T. GUERRA (org). Rio de Janeiro, Bertrand Brasil, p. 211- 252, 2012.

DEMEK, J. (Ed) Manual of detailed geomorphological mapping. Praga: Comm. Goomorph. Surv. Mapping. IGU, 1972. 368p.

EMBRAPA, Empresa Brasileira de Pesquisas Agropecuárias. Sistema brasileiro de classificação de solos - SIBICS. 2ed. Rio de Janeiro: EMBRAPA-SPI, 2006. 306 p.

FONSÊCA, D. N. Reconstrução da paisagem geomorfológica através da assinatura geoquímica dos eventos deposicionais da bacia do rio Capibaribe-Mirim, 
Pernambuco. Recife, PE. 167f. 2012. Dissertação de Mestrado, Universidade Federal de Pernambuco, 2012.

FONSECA, D. N., CORREA, A. C. B., SILVA, A. C. Compartimentação Geomorfológica da Região Metropolitana do Recife (RMR) a partir da análise morfoestrutural. Geo UERJ, Rio de Janeiro v. 29, p. 201-219, 2016.

GIRÃO, O.; CORRÊA, A. C. B.; GUERRA, A. J. T. Influência da climatologia rítmica sobre áreas de risco: o caso da Região Metropolitana do Recife para os anos de 2000 e 2001. Revista de Geografia, UFPE/DCG-NAPA: Recife, Jan/Abr v.23, no1, p. 03-41, 2006.

GUERRA, Antônio José Teixeira; MARÇAL, Mônica dos Santos. Geomorfologia Ambiental. 3를 ed. Rio de Janeiro, Bertrand Brasil, 2010, 190p.

HORTON, Robert E. Erosional development of streams and their drainage basins; hydrophysical approach to quantitative morphology, Bulletin of the Geological Society of America, V. 56, p. 275-370, 1945.

IBGE, Instituto Brasileiro de Geografia e estatística. Manual Técnico de Geomorfologia. Rio de Janeiro, IBGE, 2º edição, 2009, 175 pp.

LIMA, Walter de Paula. Hidrologia florestal aplicada ao manejo de bacias hidrográficas, ESALQ/USP, $2^{\circ}$ ed. Piracicaba, 2008, 253p.

PIRES, José Salatiel Rodrigues; SANTOS, José Eduardo dos; DEL PRETTE, Marcos Estevan. A Utilização do Conceito de Bacia Hidrográfica para a Conservação dos Recursos Naturais. In: SCHIAVETTI, Alexandre; CAMARGO, Antônio F. M. (editores). Conceitos de Bacias Hidrográficas: teorias e aplicações. Ilhéus, BA: Editus, 2002. 293p.

SAADI, A. Ensaio sobre a morfotectônica de Minas Gerais: tensões intraplaca, descontinuidades crustais e morfogênese. Belo Horizonte, MG. 1991. 300f. Tese Professor Titular, Universidade Federal de Minas Gerais, 1991.

SCHUMM, Stanley A. The Fluvial System, Caldwell, The Blackburn Press, 1977, 337p.

STEVAUX, José Candido. Geomorfologia Fluvial, Oficina de Textos, São Paulo, 2017, 336p.

SILVA, Adriana Cassiano da. Reconstrução quaternária da dinâmica geomorfológica a partir das análises dos depósitos do baixo curso do rio Capibaribe/PE, 2016, $208 f$. Dissertação de Mestrado apresentado ao Programa de Pós-graduação em Geografia da Universidade Federal de Pernambuco, Recife, 2016.

SOUZA, Alexandre dos Santos. Caracterização Geomorfológica, Morfotectônica e Morfométrica da folha Itaporoca 1:25.000, Paraíba, Brasil, 2016, 112f. Dissertação de Mestrado apresentada ao programa de pós-graduação em Geografia da Universidade Federal da Paraíba, João Pessoa, 2016.

TEODORO, Valter Luiz Iost; TEIXEIRA, Denilson; COSTA, Daniel Jadyr Leite; FULLER, Beatriz Buda $O$ conceito de Bacia Hidrográfica e a Importância da caracterização Morfométrica para o entendimento da dinâmica ambiental local, Revista UNIARA, $n^{\circ} 20, p$. 137-156, 2007.

TONELLO, Kelly Cristina. Análise hidroambiental da bacia hidrográfica da Cachoeira das Pombas, Guanhães, MG. 2005, 85f. Dissertação de Mestrado - Programa de PósGraduação em Ciência Florestal, Viçosa, 2005. 
TUCCI, Carlos E. M. (Org.) Hidrologia; Ciência e Aplicação, $4^{\circ}$ ed. Porto Alegre: Ed. Da UFRGS/ABRH, 2009, 943p.

\section{NOTAS DE AUTOR}

\section{CONTRIBUIÇÃO DE AUTORIA}

Carla Suelania da Silva - Concepção. Coleta de dados, Análise de dados, Elaboração do manuscrito, revisão e aprovação da versão final do trabalho

Osvaldo Girão - Participação ativa da discussão dos resultados; Revisão e aprovação da versão final do trabalho.

\section{FINANCIAMENTO}

Fundação de Amparo à Ciência e Tecnologia de Pernambuco - FACEPE

CONSENTIMENTO DE USO DE IMAGEM

Não se aplica

\section{APROVAÇÃO DE COMITÊ DE ÉTICA EM PESQUISA}

Não se aplica

\section{CONFLITO DE INTERESSES}

Não se aplica

\section{LICENÇA DE USO}

Este artigo está licenciado sob a Licença Creative Commons CC-BY. Com essa licença você pode compartilhar, adaptar, criar para qualquer fim, desde que atribua a autoria da obra.

\section{HISTÓRICO}

Recebido em: 17-06-2019

Aprovado em: 14-04-2020 